\title{
Diisocyanate-induced asthma in Switzerland: long-term course and patients' self-assessment after a 12-year follow-up
}

\author{
Martin Rüegger, Doreen Droste, Markus Hofmann, Marcel Jost and David Miedinger
}

\begin{abstract}
Background: Isocyanates are among the most common causes of occupational asthma $(\mathrm{OA})$ in Switzerland. Patients with OA have been shown to have unfavourable medical, socioeconomic and psychological outcomes. We investigated long-term asthma and the socio-economic outcomes of diisocyanate-induced asthma (DIA) in Switzerland.
\end{abstract}

Patients and methods: We conducted an observational study on 49 patients with DIA and followed 35 of these patients over a mean exposure-free interval of $12 \pm 0.5$ (range 11.0-13.0) years. At the initial and follow-up examinations, we recorded data on respiratory symptoms and asthma medication; measured the lung function; and tested for bronchial hyperreactivity. We allowed the patients to assess their state of health and overall satisfaction using a visual analogue scale (VAS) at these visits.

Results: The 35 patients whom we could follow had a median symptomatic exposure time of 12 months, interquartile range (IQR) 26 months and a median overall exposure time of 51 (IQR 104) months. Their subjective symptoms $(p<0.001)$ and the use of asthma medication $(p=0.002)$, particularly the use of inhaled corticosteroids $(p<0.001)$, decreased by nearly $50 \%$. At the same time, the self-assessment of the patients' state of health and overall satisfaction increased considerably according to both symptomatology and income. In contrast, slight reductions in terms of FVC\% predicted from $102 \%$ to $96 \%$ ( $p=0.04)$, of FEV1\% predicted from $91 \%$ to $87 \%(p=0.06)$ and of the FEV1/FVC ratio of 3\%; ( $p=0.01)$ were observed while NSBHR positivity did not change significantly. In univariate as well as multivariate logistic analyses we showed significant associations between age, duration of exposure and FEV1/FVC ratio with persistent asthma symptoms and NSBHR.

Conclusions: We found that the patients' symptoms, the extent of their therapy and the decrease in their lung volumes during the follow-up period were similar to the findings in the literature. The same hold true for some prognostic factors, whereas the patients' self-assessment of their state of health and overall satisfaction improved considerably.

Keywords: Occupational asthma, Diisocyanate asthma, Long-term follow-up, Self-assessment

\section{Background}

For more than two decades diisocyanates, a group of highly reactive and widely used chemicals, were one of the most common causes of occupational asthma in industrialised countries [1] though the incidence of diisocyanate induced occupational asthma (DIA) seems to have decreased over recent years [2-4].

\footnotetext{
* Correspondence: david.miedinger@suva.ch

Department of Occupational Medicine, Swiss National Insurance Fund Suva, Fluhmattstr. 1, CH 6002 Lucerne, Switzerland
}

Follow-up studies published during the last 20 years have shown a poor outcome for DIA even in the absence of additional exposure to the offending agent. Approximately $50-82 \%$ of persons who suffer from DIA do not recover completely and need continuous anti-asthmatic therapy [5-8]. According to the literature, recovery depends on a series of prognostic factors, such as the lung volume at the beginning of exposure [9], the time of diagnosis $[10,11]$, the degree of bronchial hyperreactivity [9], the length of exposure time $[12,13]$, the duration of

\section{Biomed Central}

(c) 2014 Rüegger et al.; licensee BioMed Central Ltd. This is an Open Access article distributed under the terms of the Creative Commons Attribution License (http://creativecommons.org/licenses/by/2.0), which permits unrestricted use, distribution, and reproduction in any medium, provided the original work is properly credited. 
symptomatic exposure $[11,14,15]$ and possibly the duration of follow-up $[16,17]$.

Until the early 1990s, there were only clinical followup studies on DIA that explored short time periods $[7,8,12,13,18]$. Therefore, we decided to do a long-term study with our own DIA patients beginning in 1993 and covering a time period of at least 10 years. Subsequently, in 2000 and in 2003, two carefully conducted studies on the outcome of patients with DIA over a 12-year follow-up were published $[19,20]$.

The aim of our study was to investigate the long-term outcome of DIA in a non-preselected group of patients; we focussed on asthma symptoms, the need for treatment, changes in lung function and on nonspecific bronchial hyperreactivity (NSBHR). Further we wanted to evaluate the factors that were associated with persistent asthma symptoms and NSBHR [16] as well as the individual state of health and overall satisfaction at follow-up.

\section{Materials and methods}

All patients with suspected DIA reported to Suva (Swiss Accident Insurance Fund) between 1993 and 1995 were eligible for the study. Patients were included if the combination of their history and their spirometric findings, peak expiratory flow (PEF) recordings or inhalation challenge test results confirmed the diagnosis [21]. All of the patients gave their informed consent to participate in the study.

The patients who were admitted to our study had been exposed to one or more of the following diisocyanates: toluene diisocyanate (TDI), diphenylmethane diisocyanate (MDI), hexamethylene diisocyanate (HDI), naphthylene diisocyanate (NDI) or isophorone diisocyanate (IPDI) or one of their reactive prepolymers either continuously or intermittently.

We performed an uncontrolled observational study over 12 years. For each subject, a detailed clinical and occupational history was recorded and lung function and bronchoprovocation tests were performed between 1993 and 1995, i.e., at the time of diagnosis (T0), and again in 2006, at the time of re-evaluation (T1). The participants' longitudinal results are presented with data available at $\mathrm{T} 0$ and $\mathrm{T} 1$.

The data were recorded by one of Suva's occupational physicians at three different locations (Lausanne, Lucerne and Winterthur) during 1993-1995 (T0) and again in 2006 (T1) by DD as part of her doctoral thesis except two patients who were interviewed and examined by $\mathrm{MH}$, and two others by their family doctors because of the patients' limited mobility. To ensure uniformity of questioning a checklist was used that had been established before. Most of the data have been collected routinely when evaluating notified cases in order to determine causality of occupational asthma $(\mathrm{OA})$.
The subject's history included upper airway symptoms, such as nasal flow and itching, and lower airway symptoms, such as irritation, cough, wheezing, dyspnoea, chest tightness, and their temporal relationship to work. Additionally, information on the use of asthma medications, smoking habits, isocyanate exposure and current workplace as well as socioeconomic aspects were gathered.

In 2006, the subjects were asked to report their state of health as well as their overall satisfaction using two identical $10 \mathrm{~cm}$ neutral VASs. These measures reflect subjective factors in a global manner but correlate highly with several standard questionnaires and are accurate and useful for assessing symptoms, such as pain, anxiety and psychological distress [22]. Patients had to enter one mark retrospectively for the time T0 and another mark for the current time, T1. The second VAS mark could not be set until the first one was covered. The left end of the scale $(0 \mathrm{~cm})$ signified the worst rating conceivable, whereas the right end $(10 \mathrm{~cm})$ indicated the optimal rating.

Between 1993 and 1995, all patients had a walk-through visit by an occupational physician to confirm exposure to isocyanates and to exclude relevant co-exposure to other sensitizers or irritants that might have caused the reported symptoms (results not reported).

All of the patients underwent routine clinical examinations as well as standard lung function tests at one of Suva's three occupational medical centres. The tests conducted at time $\mathrm{T} 0$ and $\mathrm{T} 1$ included forced vital capacity (FVC), forced expiratory volume in 1 second (FEV1) and the FEV1/FVC ratio, which in most cases were measured by whole-body plethysmography (Jaeger MasterLab Germany, Vmax Autobox, VIASYS Healthcare Inc., SensorMedics, California, USA). The values published by the European Respiratory Society were used as reference values [23]. A significant obstructive ventilatory impairment was assumed to be present when the FEV1/FVC ratio was $<0.7$ [24].

To test NSBHR with acetyl- $\beta$-methylcholine chloride inhalation, Mefar dosimeters (Mefar MB3, Brescia, Italy) were used. The results were expressed as the cumulative doses required to provoke an FEV1 reduction of $20 \%$ $\left(\mathrm{PD}_{20}\right)$ graded according to the ATS scheme which was slightly modified [25]. If the FEV1 was $<70 \%$ of the predicted value, the test was not performed, and the reversibility was checked by inhaling two puffs of salbutamol $(200 \mu \mathrm{g}$ DA). Generally we defined NSBHR in the participants as having a fall in FEV1 of $>20 \%$ by inhaling $\leq 2 \mathrm{mg}$ methacholine or having an increase in FEV1 of $>10 \%$ after inhalation of salbutamol.

To confirm respiratory tract sensitisation to diisocyanates at T0, 31 of the 49 patients underwent a specific-inhalation challenge in the Thurgau-Schaffhausen Alpine Clinic in Davos according to a standardised protocol with the relevant diisocyanates or isocyanate-containing products. 
Tests were positive if an FEV1 decrease of at least $20 \%$ could be demonstrated and if the dose response curve showed a typically shaped immediate, late or dual reaction [26].

To compare the results between the beginning and the end of the follow-up examinations, only complete data sets were accounted for; i.e., those of dropouts were discarded. In order to check for prognostic factors we also stratified participants according to their FEV1\% predicted, FEV1/FVC ratio at T0 and a change in FEV1\% predicted between $\mathrm{T} 0$ and $\mathrm{T} 1$.

Continuous variables are reported as a mean \pm standard deviation (SD) or median plus interquartile range (IQR) when non-normally distributed. Statistical tests applied were the Kolmogorov-Smirnov, the McNemar's-, paired t-, Sign-, Wilcoxons-Mann-Whitney- and the chi-squared test. After performing univariate analyses, a logistic regression analysis with staggered inclusion of co-variates was performed to evaluate the effects of different variables on dependent variables such as "persistent asthma symptoms" and "persistent bronchial hyperresponsiveness at follow-up". In the "a priori" models we selected some variables (age at diagnosis, total exposure time, exposure time with symptoms) that were already shown to be associated with asthma outcome [16]. In the "a posteriori" models we included co-variates in whom univariate analyses showed significant or borderline associations with the dependent variables. Statistical analyses were performed by applying the PSPP software package [27]. To calculate mean values \pm SD, median values and IQRs, Microsoft Excel for Mac Version 14.3.9 software was used. A p $<0.05$ was considered to be statistically significant.

\section{Results}

Forty-nine patients (47 males, 2 females; mean age, $38 \pm 13$ years) were considered for inclusion into the study. These patients represented all individuals who claimed compensation between 1993 and 1995 and for whom the diagnosis of DIA could be established. Most of the study participants were car spray painters, industrial spray painters, furniture spray painters, carpenters and cabinet makers (49\%), followed by polyurethane foam casters and moulders (37\%) and other craftsmen (14\%).

We observed that $86 \%$ of the subjects were no longer being exposed to isocyanates when the diagnosis of OA was made (T0). They had ended their exposure on average one month before the investigation (range, 30 months before to 7 months thereafter) because Suva declared 44 of them unsuitable for further isocyanate-related occupational activities (declaration of "unsuitability" [DOU]) [28]. Five patients could not be declared unsuitable because three of them were self-employed persons, one received an invalidity pension for a non-occupational disease and one was affected from DIA very early during his apprenticeship so that a DOU was not indicated. In practice, the DOU resulted in nearly all of the patients changing their workplace or their employer. The median overall isocyanate exposure time of the whole cohort was 57 months (IQR 108 months), and the median symptomatic exposure time was 16 months (IQR 30 months).

After a mean interval of 12 years (range, 11.0-13.0 years), 35 of the 49 patients could be contacted and agreed to be re-examined, corresponding to a re-examination rate of $71.4 \%$. Figure 1 summarizes the flow of patients and the reasons for non-follow up. Twenty-two subjects (63\%) were still working. One of them remained at the original workplace as a car spray painter but had switched to nonisocyanate-containing varnishes, 4 (11\%) had relocated to completely isocyanate-free workplaces within the same company, and 17 (49\%) had changed their job as well as their employer to avoid further isocyanate exposure. Thirteen subjects were no longer occupationally active, 7 due to premature or regular retirement; 3 were on social welfare, 2 were unemployed and one was on longterm sick leave unrelated to DIA.

The characteristics of the 35 participating subjects and the 14 dropouts are shown in Table 1. Except for the lower $\mathrm{PD}_{20}$ at $\mathrm{T} 0$ for those that were not re-examined later, the other variables did not significantly differ from those of the individuals that were re-investigated for this study.

Table 2 represents the changes in symptoms, asthma therapy, health status and overall satisfaction for those participants for whom follow-up data was available. It shows a significant decline in the frequency of symptoms, use of asthma medication - especially inhaled corticosteroids - and an increase in subjective health status and overall satisfaction.

Table 3 summarizes the results of pulmonary function tests for the 35 subjects who were re-examined for this study. Lung function values were slightly lower at T1 compared to T0 reaching the level of significance only for $\mathrm{FEV} \%$ predicted and for the FEV1/FVC ratio. 34 of 35 participants were tested for NSBHR either by methacholine challenge or by bronchodilatation with salbutamol. While 23 subjects (68\%) were positive at the time of diagnosis their number decreased to 17 (50\%) at T1, a result that did not reach statistical significance $(\mathrm{p}=0.22)$. When focussing on the 26 participants whose tests were done by the same method on both occasions ( 22 by methacholine and 4 by bronchodilatation) the number of positive results again dropped from 18 to 15 (14 methacholine and 4 bronchodilatation tests at T0; 14 methacholine and 1 bronchodilatation test at T1) a decline that again did not reach statistical significance. The same was true for those 22 patients who underwent methacholine challenge tests (median of $\mathrm{PD}_{20} 0.95 \mathrm{mg}$ (IQR $1.68 \mathrm{mg}$ ) at T0 versus $0.70 \mathrm{mg}$ (IQR $1.66 \mathrm{mg} ; \mathrm{p}=0.81$ ) at T1. 


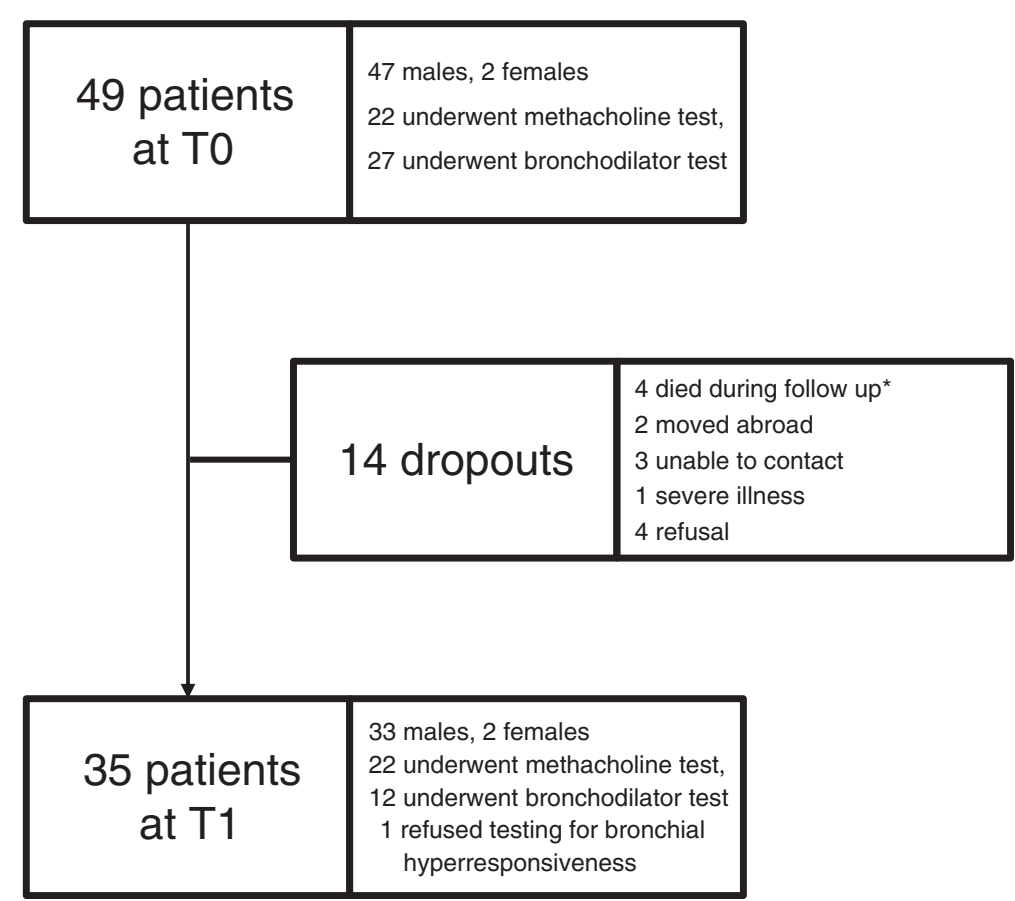

Figure 1 Flow-chart of recruited patients. Legend: $\mathrm{T} 0=$ time of diagnosis, $\mathrm{T} 1=$ time of re-evaluation. * Reasons for death (coronary heart disease $(n=1)$, aspiration pneumonia $(n=1)$, unknown $(n=2))$.

Table 1 Baseline characteristics of participants and dropouts at TO $(n=49)$

\begin{tabular}{lccc}
\hline & $\begin{array}{c}\text { Participants } \\
\text { (n=35) }\end{array}$ & $\begin{array}{c}\text { Dropouts } \\
\text { (n=14) }\end{array}$ & p-value \\
\hline Age at diagnosis & $39 \pm 13$ & $36 \pm 13$ & 0.53 \\
Sex (males) & $33(94 \%)$ & $14(100 \%)$ & 1.0 \\
FVC\% predicted & $102 \pm 17$ & $97 \pm 13$ & 0.37 \\
FEV1\% predicted & $91 \pm 16$ & $90 \pm 16$ & 0.89 \\
FEV1/FVC & $75 \pm 9$ & $74 \pm 10$ & 0.50 \\
PD 20 (mg) & $0.95(1.7)$ & $0.30(0.5)$ & 0.03 \\
NSBHR positivity & $23(68 \%)$ & $11(92 \%)$ & 0.13 \\
Total exposure time (months) & $51(104)$ & $74(89)$ & 0.77 \\
Time with symptoms (months) & $12(26)$ & $24(31)$ & 0.38 \\
Smokers & $10(29 \%)$ & $6(43 \%)$ & 0.5 \\
Pack-years* & $25(24)$ & $13(14)$ & 0.16 \\
Upper airway symptoms & $28(80 \%)$ & $11(79)$ & 1.0 \\
Asthma symptoms & $34(97 \%)$ & $14(100)$ & 1.0 \\
Asthma medication & $31(91 \%)$ & $8(89)$ & 1.0 \\
\hline
\end{tabular}

Legend: $F V C=$ forced expiratory vital capacity. FEV1 = forced expiratory volume in 1 second. NSBHR = nonspecific bronchial hyperreactivity. $\mathrm{PD} 20=$ provocative dose of methacholine producing a fall in FEV1 of 20\%. *Pack-years for smokers and ex-smokers added. Data is presented as mean $\pm S D$, median and interquartile range (IQR) or number (\%).
Tables 4, 5 and 6 show baseline characteristics according to lung function at $\mathrm{T} 0$ and lung function loss during follow-up. Age, FEV1/FVC, smoking variables and exposure data in those individuals with FEV1 $<80 \%$ predicted at $\mathrm{T} 0$ were not different from those with better lung function. The same was true for those with $\geq 15 \%$ loss of FEV1\% predicted between $\mathrm{T} 0$ and $\mathrm{T} 1$. Individuals with a FEV1/FVC ratio $<0.7$ at T0 had a lower FEV1\% predicted and a higher tobacco consumption than those with higher FEV1/FVC ratio.

Table 2 Change in symptoms, therapy and visual analogue scale (VAS) ratings between T0 and T1 $(n=35)$

\begin{tabular}{lccc}
\hline & T0 & T1 & p-value \\
\hline Upper airway symptoms & $28(80 \%)$ & $9(26 \%)$ & $<0.001$ \\
Asthma symptoms & $34(97 \%)$ & $20(57 \%)$ & $<0.001$ \\
Use of asthma medication* & $31(91 \%)$ & $19(56 \%)$ & 0.002 \\
Short acting beta2 agonists & $19(56 \%)$ & $13(38 \%)$ & 0.18 \\
Long acting beta2 agonists & $10(29 \%)$ & $10(29 \%)$ & 1.0 \\
Inhalable corticosteroids & $26(76 \%)$ & $10(29 \%)$ & $<0.001$ \\
Smokers & $10(29 \%)$ & $14(40 \%)$ & 0.05 \\
VAS (cm) health status & $1.2(2.9)$ & $8.0(4.0)$ & $<0.001$ \\
VAS (cm) overall satisfaction & $2.1(6.1)$ & $8.3(3.4)$ & $<0.001$ \\
\hline
\end{tabular}

Legend: Upper airway symptoms (conjunctivitis, rhinitis, hoarseness, pharyngeal irritant sensations); asthma symptoms (irritation, wheezing, chronic cough, chest tightness and dyspnoea); VAS = visual analogue scale. Data is presented as mean $\pm S D$, median and interquartile range (IQR) or number (\%). ${ }^{*} \mathrm{n}=34$. 
Table 3 Results of lung function and hyperreactivity testing at T0 and T1

\begin{tabular}{lccc}
\hline & T0 & T1 & p-value \\
\hline FVC\% predicted & $102 \pm 17$ & $96 \pm 17$ & 0.04 \\
FEV1\% predicted & $91 \pm 16$ & $87 \pm 18$ & 0.06 \\
FEV1/FVC & $76 \pm 9$ & $73 \pm 8$ & 0.01 \\
PD $_{20}(\mathrm{mg})$ & $0.95(1.7)$ & $0.70(1.7)$ & 0.81 \\
\hline
\end{tabular}

Legend: $F V C=$ forced vital capacity. FEV1 $=$ forced expiratory volume in one second. PD20 = provocative dose of methacholine causing a $20 \%$ fall in FEV1. NSBHR = nonspecific bronchial hyperreactivity

Data is presented as mean $\pm \mathrm{SD}$ or median and interquartile range (IQR).

The results of the multivariate logistic regression analysis can be seen in Table 7. In the "a priori" models age was associated with persistent asthma symptoms at follow-up $(\mathrm{p}=0.02)$ and persistent NSBHR was associated with total exposure time $(\mathrm{p}=0.04)$. In the predictive "a posteriori" model the degree of airflow limitation at diagnosis was associated with persistent asthma symptoms at T1 $(\mathrm{p}=0.05)$. Asthma medication $(\mathrm{p}<0.001)$ and age $(\mathrm{p}=0.06)$ at $\mathrm{T} 1$ were associated with asthma symptoms both at follow up.

\section{Discussion}

The aim of our 12-year follow-up study was to investigate the long-term outcome of patients with DIA, to check for possible prognostic factors and to compare these results obtained in Switzerland with those reported in the literature, primarily of the two previously cited larger cohorts of patients with DIA $[19,20]$. We found that at a mean of 12 years after removal from exposure to the offending diisocyanates, the majority of the patients reported fewer respiratory symptoms, decreased asthma medication use and a better self-reported overall health status while lung function values at follow up were slightly lower compared to normal.

At T1, 14 of the initially evaluated 49 patients at T0 could not be retraced (dropout rate 28.6\%). The 35

Table 4 Baseline characteristics of patients according to their FEV1 at T0

\begin{tabular}{lccc}
\hline & $\begin{array}{c}\text { FEV1 } \geq \mathbf{8 0} \% \\
\text { pred. }(\mathbf{n}=\mathbf{2 8})\end{array}$ & $\begin{array}{c}\text { FEV1 }<\mathbf{8 0} \% \\
\text { pred. }(\mathbf{n}=\mathbf{7})\end{array}$ & p-value \\
\hline Age & $38 \pm 13$ & $42 \pm 10$ & 0.44 \\
FEV1/FVC & $77 \pm 8$ & $72 \pm 11$ & 0.20 \\
Current smoking & $8(29 \%)$ & $2(29 \%)$ & 1.0 \\
Pack years* & $7(15)$ & $20(13)$ & 0.37 \\
Total exposure time (months) & $51(99)$ & $53(129)$ & 0.68 \\
Symptomatic exposure & $13(34)$ & $8(14)$ & 0.22 \\
time (months) & & & \\
\hline
\end{tabular}

Legend: $F V C=$ forced expiratory vital capacity. FEV1 = forced expiratory volume in 1 second. *Pack-years for smokers and ex-smokers added.

Data is presented as mean $\pm S D$, median and interquartile range (IQR) or number (\%).
Table 5 Baseline characteristics of patients according to their FEV1/FVC ratio at T0

\begin{tabular}{lccc}
\hline & $\begin{array}{c}\text { FEV1/FVC } \geq \mathbf{0 . 7} \\
(\mathbf{n}=\mathbf{2 5})\end{array}$ & $\begin{array}{c}\text { FEV1/FVC }<\mathbf{0 . 7} \\
(\mathbf{n}=\mathbf{1 0})\end{array}$ & p-value \\
\hline Age (years) & $37 \pm 14$ & $42 \pm 9$ & 0.34 \\
FEV1\% predicted & $95 \pm 13$ & $83 \pm 20$ & $<0.001$ \\
Current smoking & $7(28 \%)$ & $3(30 \%)$ & 1.00 \\
Pack years* & $5(12)$ & $20(20)$ & $<0.001$ \\
Total exposure time (months) & $44(80)$ & $145(143)$ & 0.16 \\
$\begin{array}{l}\text { Symptomatic exposure } \\
\text { time (months) }\end{array}$ & $11(15)$ & $19(33)$ & 0.31 \\
\hline
\end{tabular}

Legend: $\mathrm{FVC}=$ forced expiratory vital capacity. $\mathrm{FEV} 1$ = forced expiratory volume in 1 second. *Pack-years for smokers and ex-smokers added.

Data is presented as mean $\pm S D$, median and interquartile range (IQR) or number (\%).

patients who could be followed until T1 represent a small sample size, a fact that weakened the informative value of our results. Piirilä ( $8 \%$ non-responders in their first phase questionnaire survey) and, particularly, Padoan and coworkers (no non-responders) did clearly better in this regard. Nevertheless, the $71.4 \%$ who re-participated in our study were within the range of other but shorter follow-up studies [15,29-32]. When analysing our data retrospectively, dropouts were having a more pronounced bronchial hyperreactivity $(\mathrm{p}=0.03)$ at diagnosis compared to participants. With respect to all the other variables such as smoking status, job groups (data not shown), age, the presence of airway symptoms, the level of FVC and FEV1\% predicted as well as the FEV1/FVC ratio or the overall exposure time period, we could not find any significant differences between study participants and dropouts. Thus we believe that the participants represent fairly well the whole study group, a fact that might outweigh to some extent its small sample size.

Based on the average number of the Swiss working population of 4 millions during 1993 - 1995 (Swiss

Table 6 Baseline characteristics of patients according to their FEV1 loss between T0 and T1

\begin{tabular}{lccc}
\hline & $\begin{array}{c}\text { FEV1 loss } \\
<\mathbf{1 5 \%}(\mathbf{n}=\mathbf{2 8})\end{array}$ & $\begin{array}{c}\text { FEV1 loss } \\
\mathbf{2 1 5 \%}(\mathbf{n = 7})\end{array}$ & p-value \\
\hline Age & $37 \pm 13$ & $45 \pm 10$ & 0.11 \\
FEV1\% pred.at T0 & $90 \pm 17$ & $98 \pm 13$ & 0.25 \\
FEV1/FVC at T0 & $77 \pm 9$ & $72 \pm 7$ & 0.25 \\
Current smoking & $8(29 \%)$ & $2(29 \%)$ & 1.0 \\
Pack years* & $11(17)$ & $11(17)$ & 0.42 \\
Total exposure time (months) & $46(91)$ & $62(169)$ & 0.32 \\
$\begin{array}{l}\text { Symptomatic exposure } \\
\text { time (months) }\end{array}$ & $11(19)$ & $19(49)$ & 0.40 \\
\hline
\end{tabular}

Legend: $F V C=$ forced expiratory vital capacity. FEV1 = forced expiratory volume in 1 second. *Pack-years for smokers and ex-smokers added. Data is presented as mean $\pm S D$, median and interquartile range (IQR) or number (\%). 
Table 7 Multivariate logistic regression analysis of predictors for persistent asthma at follow-up

\begin{tabular}{|c|c|c|c|c|}
\hline \multirow[b]{4}{*}{ Dependent variables } & \multicolumn{2}{|c|}{ "A priori" } & \multicolumn{2}{|c|}{ "A posteriori" } \\
\hline & & & \multirow{3}{*}{$\begin{array}{c}\text { Predictive } \\
\text { Model } 3 \\
\text { Persistent asthma } \\
\text { symptoms at follow-up }\end{array}$} & \multirow{3}{*}{$\begin{array}{c}\text { Descriptive } \\
\text { Model } 4 \\
\text { Persistent asthma } \\
\text { symptoms at follow-up }\end{array}$} \\
\hline & Model 1 & Model 2 & & \\
\hline & $\begin{array}{c}\text { Persistent asthma } \\
\text { symptoms at follow-up }\end{array}$ & $\begin{array}{l}\text { Persistent NSBHR } \\
\text { at follow-up }\end{array}$ & & \\
\hline \multicolumn{5}{|l|}{ Co-variates } \\
\hline Age at T0 & $0.08(p=0.02)$ & $0.03(p=0.35)$ & $0.04(p=0.27)$ & \\
\hline Age at $\mathrm{T1}$ & & & & $0.09(p=0.06)$ \\
\hline Total exposure time & & $-0.02(p=0.04)$ & & \\
\hline Symptomatic exposure time & $0.01(p=0.37)$ & $0.03(p=0.10)$ & & \\
\hline Upper airway symptoms at T0 & & & $-1.91(p=0.12)$ & \\
\hline Upper airway symptoms at $\mathrm{T} 1$ & & & & $1.36(p=0.29)$ \\
\hline FEV1/FVC at T0 & & & $-0.11(p=0.05)$ & \\
\hline Asthma medication at T1 & & & & $2.85(p<0.001)$ \\
\hline Intercept & -2.90 & -0.32 & 9.01 & -5.98 \\
\hline$R^{2}$ & 0.22 & 0.28 & 0.39 & 0.55 \\
\hline
\end{tabular}

Federal Statistical Office) the 49 DIA cases correspond to a yearly incidence rate of 4.1 cases/million which is somewhat higher than in France by ONAP indicating 3.5 cases/million [33] but considerably lower than the 10.8 cases/million reported by the PROPULSE program in Québec, Canada [34]. To note that both these sentinel programs became active during the 1990ies i.e. during the same time period when we were following-up our patients and - more important - that we report on legally compensated cases only unlike those published from Québec and from France.

Removing an asthmatic worker from the offending agent leads to an improvement in asthma severity, a fact that was confirmed by Rachiotis and co-workers [16] when doing a systematic literature review and metaanalysis on the outcome of occupational asthma after cessation of exposure. The authors found a pooled rate of symptomatic recovery of $32 \%$ (95\% CI 26\%-38\%). This finding is in agreement with the results of a recent review issued by Baur and co-workers [21], who found that, on average, $33.7 \%$ of patients (95\% CI $23.6 \%-45.6 \%$ ) no longer exhibited symptoms after complete cessation of exposure to the offending agent. These results indicate that usually more than $50 \%$ of the subjects remain symptomatic, which is in line with our figures showing that $57 \%$ of the patients continued to complain of asthma symptoms at follow up, a finding that is slightly better than that observed in the studies by Piirilä and Padoan $[19,20]$, in which more than two thirds of the patients remained asthmatic.

In our study most of the patients were still on antiasthmatic medication at follow-up; more than half of them were taking it on a regular basis, whereas 10 were still inhaling corticosteroids. These results are comparable to those of both the Piirilä and the Padoan studies, in which $66 \%$ and $60 \%$, respectively, of the patients required some form of anti-asthmatic treatment at the end of their follow-up, approximately half of them again on a regular basis in the Piirilä study [19]. According to an extended literature survey that was conducted by the Agency for Healthcare Research and Quality (AHRQ), the proportion of OA patients who require medication after cessation of exposure ranges from $17 \%$ to $100 \%$, depending to a great extent on the characteristics of the cohort and on exposure. Furthermore, the AHRQ data suggest that 4 years after removal of the offending low-molecularweight agent, approximately half of the patients are still under treatment [35], which is in line with what we have observed.

In contrast to the Piirilä and the Padoan studies, we asked the patients to assess their individual state of health as well as their overall satisfaction using a VAS. To the best of our knowledge, these factors have not been addressed in another comparable long-term DIA study. On a group basis, we observed a statistically significant increase in self-reported health status and overall satisfaction between $\mathrm{T} 0$ and $\mathrm{T} 1$, results that were comparable to those of the Karvala study, in which the overall quality of life parameter in patients with occupational asthma to moulds was reported to be between 6.5 and 7.4 [36]. When we stratified our VAS ratings according to the presence or the absence of symptoms, we observed that those without asthma symptoms at follow-up were reporting even better satisfaction than those with persistent 
symptoms (data not shown). Assuming that by far the majority of "normal persons" would not set their VAS mark precisely on 10 but rather somewhat lower, our results for the group without symptoms at follow-up do not likely differ from what could be expected from healthy people.

We admit that VAS results have to be interpreted with caution. First of all one can argue that patients who could not be followed up - dropouts - would have been more seriously diseased judging their quality of life significantly lower than the participants thus biasing the observed results in a too optimistic direction. However we think that this hypothesis is not very probable, as - with the exception of $\mathrm{PD}_{20}$ - there were no significantly different baseline characteristics between participants and dropouts (Table 1). Secondly there is no doubt that any selfassessment, especially if done retrospectively, is subjective and can thus be biased. However we had no indication for subjects to under or over report their state of health at T0 or T1 except that - in theory - some over-reporting could have been expected because the interviewers were physicians who were employed by Suva the compensating body. Such a tendency could have biased the VAS markings towards a lower level at T0 as well as at T1 thus not decisively change the absolute amount of improvement we observed.

Complete cessation of exposure to the offending agent improves symptoms as well as lung function [37] but is associated with worse socioeconomic outcomes [15,35,38], thereby increasing anxiety and depressive symptoms [31,39-41] that, in turn, have a negative impact on asthma outcome. When examining the data on socioeconomic factors at $\mathrm{T} 1$, we found that those 13 patients who were not working lost on average $19.2 \%$ of their income, 7 of them after retiring regularly or prematurely, incurring an income reduction either way. Those who were still economically active (22 of 35 ) had a salary increase of $13.7 \%$ (after retraining) or a slight loss of 6\% (without retraining) [42]. To look at the impact of both symptoms and income on overall satisfaction at the end of the follow-up, we found that persisting asthmatic symptoms entailed a clearly lower VAS ranking than the loss of income. It is obvious that the latter does not reflect all aspects of possible socioeconomic problems. Nevertheless, we think that once financial problems have been managed and an alternative job is found, to the patients' satisfaction, psychological distress will be alleviated, resulting in better tolerability of the remaining symptoms, as observed by Piirilä and Keskinen [19,43].

Lung function in the participants was lower than those reported in the Piirilä and the Padoan studies (99.6\% and $98.8 \%$ predicted respectively) $[19,20]$. According to the literature, the lungs are not completely developed by late adolescence, with lung function values not plateauing until early in the third decade of life [44]. Two of our 35 subjects were only 17 and 18 years old at diagnosis, a fact that could explain the slight reduction in the average lung volumes at the beginning of the study but not an isolated decrease in FEV1.

The decreases in FVC\% predicted as well as in the FEV1/FVC ratio between $\mathrm{T} 0$ and $\mathrm{T} 1$ were small but significant, whereas the FEV1\% predicted changed only insignificantly even though the number of patients with overt airflow limitation remained numerically constant $(n=10)$. These results are again consistent with those of Piirilä, Padoan and others, indicating slight but overt lung function deterioration during follow-up.

When specifically looking at the observed small FEV1/ FVC decrease, which is based on a fixed lower limit of 0.7 instead of using calculated limits of normal, as has been recommended earlier $[45,46]$, we believe that this decrease might be attributed, at least in part, to the physiological loss of elastic recoil by ageing. This argument holds true only if one assumes that any substantial recovery of the lung volume of our subjects occurred during the approximately one-month time period between the cessation of exposure and the examination at T0, outweighing the observed volume decrease. In any case it is questionable whether the observed small lung function decreases are clinically relevant. Another possible explanation for the decrease in lung volumes might be persisting diisocyanate exposure. However, this can be largely ruled out because $86 \%$ of the subjects had been removed from any further contact by the time of T0, although 9 persons reported having had sporadic and unintended diisocyanate exposures during the follow-up period.

Overall there was a trend for a decrease in the number of individuals with NSBHR having either a positive challenge test to methacholine or a significant reversibility after inhalation of a short acting bronchodilatator. However when considering $\mathrm{PD}_{20}$ in individuals who underwent methacholine testing at the beginning and at the end of the follow up period, no significant change could be observed. It is well known that the duration of symptomatic exposure and the level of NSBHR are risk factors for persistent NSBHR and that some individuals keep their NSBHR despite complete removal from the exposing allergen in the workplace $[16,21,47]$. We believe that two factors might explain our result: Firstly our NSBHR test pairs are incomplete, potentially biasing the result in favour of those subjects doing worse; and secondly we observed an overall increase of active smokers during follow-up (Table 2), which by itself might be a risk factor for NSBHR [48].

When analysing our participants according to their lung function at $\mathrm{T} 0$ or its change during follow up (Tables 4, 5 and 6) we did not find any significant differences 
concerning age and exposure parameters between affected and non affected individuals, FEV1 and tobacco consumption for the patients with a FEV1/FVC ratio $<0.7$ (Table 5) excluded, though some of the criteria we looked at are known prognostic factors of OA $[9,16,21]$.

The presence of airflow limitation is a known prognostic factor for asthma, COPD and other (respiratory) diseases. When we compared the patients having an FEV1/FVC ratio $<0.7$ with those who were non-obstructive at T0 (Table 5) we found the former to have started with a significantly lower FEV1\% predicted and to have had a significantly higher tobacco consumption while the other parameters did not differ between the two groups (Table 5) [16,21]. Again these results are very well comparable with what has been published in the literature except for tobacco consumption that is not an accepted risk factor for DIA [6,9]. Nevertheless we assume that in some of our patients airflow limitation at T0 was due to both isocyanate as well as tobacco exposure, the latter playing an explicit role as aggravating factor as it is known that smoking adversely affects asthma outcome due to altered airway inflammation and corticosteroid insensitivity contributing therefore to a high rate of symptom persistence and lung function loss at follow-up [49]. Further it is possible that some of our subjects started their isocyanate exposure with a pre-existing airflow limitation, a hypothesis we cannot prove because we do not dispose of any medical data for the time when they started their isocyanate exposure.

When we further stratified our cohort according to the FEV1 loss that was observed between T0 and T1 (Table 6) we largely obtained the same results: The "marked decliners" (FEV1 loss $\geq 15 \%$ predicted) tended to be older, to have a lower FEV1\% predicted at T0 and a longer total diisocyanate as well as a symptomatic exposure time.

Finally we tried to identify factors that were associated with the long-term outcome such as persistent asthmatic symptoms and NSBHR by performing a multivariate logistic regression analysis. Several studies did report that duration of (symptomatic) exposure and age at diagnosis are associated with adverse outcomes of occupational and non-occupational asthma $[9,16,21]$. This is what we could confirm in the "a priori model" as age and exposure time were associated with DIA outcomes. In the "a posteriori model" the FEV1/FVC ratio was the factor that best predicted persistent asthma symptoms at follow-up. Finally age and asthma medication at follow-up were the co-variates that were associated with persistent asthma symptoms at follow-up. To note that age might be linked to the length of exposure, two variables that have not been clearly disentangled until now [9]. However in our sample age and total exposure time did not correlate at all (Pearson Correlation Coefficient $=0.11, \mathrm{p}=0.47$ ) while total exposure time showed only a moderate correlation with symptomatic exposure time (Pearson Correlation Coefficient $=0.53, \mathrm{p}<0.001$ ). Rachiotis and co-workers found - based on 2 studies only - older patients to be more likely to completely recover from NSBHR while 5 out of 6 other cited studies reported shorter durations of exposure to be associated with a better outcome in terms of physiological recovery respectively NSBHR. Rachiotis' result is supported - at least in tendency - by Baur and colleagues [21] who pointed to the fact that the data from the literature they based their report upon were mostly not significant. To conclude there is no firmly established association between NSBHR and independent variables such as age and duration of exposure while NSBHR positivity at the time of diagnosis is a negative prognostic factor $[9,21]$.

The finding of an association between the FEV1/FVC ratio at $\mathrm{T} 0$ and the persistence of asthma symptoms at $\mathrm{T} 1$ is supported by the review of Maestrelli and co-workers who stated that impaired lung function at diagnosis had a negative role on the outcome of OA though they report only isolated data on FEV1 and FVC but not on their ratio.

In retrospect, we recognised that medical examinations dating back to the start of exposure would have been very helpful enabling us to look for individuals at risk when further exposed to noxious substances at their workplaces. As part of preventive measures, we would recommend reasonable medical pre-employment or at least surveillance programs to be introduced not only for all isocyanateexposed workers but for all persons at risk to develop occupational asthma $[1,21,50,51]$.

\section{Conclusion}

In conclusion, we found that more than $50 \%$ of our 35 subjects suffering from DIA reported to remain symptomatic, had worse lung function and were in need of therapy for asthma after an exposure-free follow-up period of 12 years. In contrast, the patients' self-assessment of their health and overall satisfaction increased considerably during the observation period, which is primarily a consequence of becoming symptom free and having satisfactorily resolved their socioeconomic problems. Persistence of asthma symptoms and NSBHR was associated with age, exposure time and lung function at the time of diagnosis (T0). Our results suggest that surveillance programs as well as information on occupational risks for asthma and early symptoms recognition should be offered to the workforce thereby not excluding older and experienced workers as they are still at risk for DIA the latter being characterized by worse outcomes. Finally workers and especially patients with diagnosed occupational asthma should receive counselling on smoking cessation as continuous smoking may adversely affect asthma outcomes. 


\section{Abbreviations}

DIA: Diisocyanate asthma; NSBHR: Non-specific bronchial hyperreactivity; DOU: Declaration of unfitness; OA: Occupational asthma; PEF: Peak expiratory flow; VAS: Visual analogue scale.

\section{Competing interests}

The authors declare that they have no competing interests.

\section{Authors' contributions}

MR was involved in the initial planning of the study. He also drafted and revised the manuscript. DD performed all but four of the follow-up examinations. She also wrote a doctoral thesis evaluating additional data that were not included in the present paper. MH conducted two of the remaining follow-up examinations. MJ was the initiator of the study and the former chief occupational physician and head of Suvas' occupational medical department. DM critically revised the study results and contributed substantial medical as well as statistical input. All of the co-authors read and approved the final manuscript.

\section{Acknowledgements}

First, all the authors would like to thank all of the patients for their participation and their former and active colleagues of the occupational medical department of Suva who performed the initial medical examinations at TO as well as the on-site visits at the different work places. We extend our special appreciation to the laboratory staff from Lucerne, Lausanne and Winterthur, who performed all of the lung function tests, and finally, to B. Villiger and F. Schwarz from the former Thurgau Schaffhausen Alpine Clinic in Davos for conducting the specific bronchoprovocation tests.

\section{Funding}

The costs of the examinations as well as other expenses, such as for travelling, were covered by Suva. There was no additional third party funding.

Received: 23 August 2013 Accepted: 8 May 2014

Published: 14 May 2014

\section{References}

1. Baur X, Aasen TB, Sherwood Burge P, Heederik D, Henneberger PK, Maestrelli $P$, Schlünssen V, Vandenplas $O$, Wilken D: The management of work-related asthma guidelines: a broader perspective. Respir Rev 2012, 21:125-139.

2. Paris C, Ngatchou-Wandji J, Luc A, McNamee R, Bensefa-Colas L, Larabi L, Telle-Lamberton M, Herin F, Bergeret A, Bonneterre V, Brochard P, Choudat D, Dupas D, Garnier R, Pairon JC, Agius RM, Ameille J: Work-related asthma in France: recent trends for the period 2001-2009. Occup Environ Med 2012, 69:391-397.

3. Buyantseva LV, Liss GM, Ribeiro M, Manno M, Luce CE, Tarlo SM: Reduction in diisocyanate and non-diisocyanate sensitizer-induced occupational asthma in Ontario. J Occup Environ Med 2011, 53:420-426.

4. Vandenplas $\mathrm{O}$, Lantin AC, D'Alpaos V, Larbanois A, Hoet P, Vandeweerdt M, Thimpont J, Speybroeck N: Time trends in occupational asthma in Belgium. Respir Med 2011, 105:1364-1372.

5. Piirilä PL, Meuronen A, Majuri M-L, Luukkonen R, Mäntylä T, Wolff HJ, Nordman $\mathrm{H}$, Alenius $\mathrm{H}$, Laitinen $\mathrm{A}$ : Inflammation and functional outcome in diisocyanate-induced asthma after cessation of exposure. Allergy 2008, 63:583-591.

6. Mapp CE, Boschetto P, Maestrelli P, Fabbri LM: Occupational asthma, state of the art. Am J Respir Crit Care Med 2005, 172:280-305.

7. Mapp CE, Corona PC, De Marzo N, Fabbri LM: Persistent asthma due to isocyanates: a follow-up study of subjects with occupational asthma due to toluene diisocyanate (TDI). Am Rev Respir Dis 1988, 137:1326-1329.

8. Lozewicz S, Assoufi BK, Hawkins R, Taylor AJ: Outcome of asthma induced by isocyanates. Br J Dis Chest 1987, 81:14-22.

9. Maestrelli $P$, Schlünssen V, Mason P, Sigsgaard T: Contribution of host factors and workplace exposure to the outcome of occupational asthma. Eur Respir Rev 2012, 21:88-96.

10. Tarlo SM, Balmes J, Balkissoon R, Beach J, Beckett W, Bernstein D, Blanc PD, Brooks SM, Cowl CT, Daroowalla F, Harber P, Lemiere C, Liss GM, Pacheco KA, Redlich CA, Rowe B, Heitzer J: Diagnosis and management of work-related asthma: American College Of Chest Physicians Consensus Statement. Chest 2008, 134(Suppl 3):1S-41S.
11. Park HS, Nahm DH: Prognostic factors for toluene diisocyanate-induced occupational asthma after removal from exposure. Clin Exp Allergy 1997, 27:145-150.

12. Pisati G, Baruffini A, Zedda S: Toluene diisocyanate induced asthma: outcome according to persistence or cessation of exposure. $\mathrm{Br} J$ Ind Med 1993, 50:60-64.

13. Rosenberg N, Garnier R, Rousselin X, Mertz R, Gervais P: Clinical and socio-professional fate of isocyanate-induced asthma. Clin Allergy 1987, 17:55-61.

14. Pisati G, Baruffini A, Bernabeo F, Cerri S, Mangili A: Rechallenging subjects with occupational asthma due to toluene diisocyanate (TDI), after long-term removal from exposure. Arch Occup Environ Health 2007, 80:298-305.

15. Gannon PFG, Weir DC, Robertson AS, Sherwood Burge P: Health., employment, and financial outcomes in workers with occupational asthma. Br J Ind Med 1993, 50:491-496.

16. Rachiotis G, Savani R, Brant A, MacNeill St J, Newman Taylor A, Cullinan P: Outcome of occupational asthma after cessation of exposure: a systematic review. Thorax 2007, 62:147-152.

17. Perfetti L, Cartier A, Ghezzo H, Gautrin D, Malo JL: Follow-up of occupational asthma after removal from or diminution of exposure to the responsible agent: relevance of the length of the interval from cessation of exposure. Chest 1988, 114:298-403.

18. Paggiaro $\mathrm{PL}$, Vagaggini $\mathrm{B}$, Dente $\mathrm{FL}$, Bacci $\mathrm{E}$, Bancalari L, Carrara M, Di Franco A, Giannini D, Giuntini C: Bronchial hyperresponsiveness and toluene diisocyanate. Long-term change in sensitized asthmatic subjects. Chest 1993, 103:1123-1128.

19. Piirilä PL, Nordman H, Keskinen HM, Luukkonen R, Salo S-P, Tuomi TO, Tuppurainen M: Long-term follow-up of hexamethylene diisocyanatediphenylmethane diisocyanate-, and toluenediisocyanate-induced asthma. Am J Respir Crit Care Med 2000, 162:516-522.

20. Padoan M, Pozzato V, Simoni M, Zedda L, Milan G, Bononi I, Piola C, Maestrelli P, Boschetto P, Mapp CE: Long-term follow-up of toluene diisocyanate-induced asthma. Eur Respir J 2003, 21:637-640.

21. Baur X, Sigsgaard T, Aasen TB, Burge PS, Heederik D, Henneberger $P$, Maestrelli P, Rooyackers J, Schlünssen V, Vandenplas O, Wilken D: Guidelines for the management of work-related asthma. ERS Task Force Report. Eur Respir J 2012, 39:529-545.

22. de Boer AGEM, van Lanschot JJB, Stalmeier PFM, van Sandick JW, Hulscher JBF, de Haes JCJM, Sprangers MAG: Is a single-item visual analogue scale as valid, reliable and responsive as multi-item scales in measuring quality of life? Qual Life Res 2004, 13:311-320.

23. Quanjer PH, Tammeling GJ, Cotes JE, Pedersen OF, Peslin R, Yernault JC: Lung volumes and forced ventilatory flows: Report working party standardization of lung function tests, European Community for steel and coal. Official statement of the European Respiratory Society. Eur Respir J 1993, 16(suppl):5-40.

24. Celli BR, MacNee W: Standards for the diagnosis and treatment of patients with COPD: a summary of the ATS/ERS position paper. Eur Respir J 2004, 23:932-946.

25. American Thoracic Society: Guidelines for methacholine and exercise challenge testing - 1999. Am J Respir Crit Care Med 2000, 161:309-329.

26. Vandenplas $\mathrm{O}$, Malo JL: Inhalation challenges with agents causing occupational asthma. Eur Respir J 1997, 10:2612-2629.

27. Plaff B, Darrington J, Stover J, Satman MH, Williams J, Kiefte M, Kobly P, van Son R: GNU PSPP. Version 0.8.2. Boston: Free Software Foundation; 2014:2014.

28. Jost M, Rast $\mathrm{H}$ : Assessment of the suitability of workers based on the Swiss Law on Accident Insurance-declaration of unsuitability/declaration of conditional suitability. [Article in German]. Ther Umsch 2007, 64:437-442.

29. Lemière $C$, Chaboillez $S$, Welman $M$, Maghni $K$ : Outcome of occupational asthma after removal from exposure: A follow-up study. Can Respir J 2010, 17:61-66.

30. Gautrin D, Ghezzo H, Infante-Rivard C, Magnan M, L'Archevêque J, Suarthana E, Malo JL: Long-term outcomes in a prospective cohort of apprentices exposed to high-molecular-weight agents. Am J Respir Crit Care Med 2008, 177:871-879.

31. Labrecque M, Khemici E, Cartier A, Malo JL, Turcot J: Impairment in workers with isocyanate-induced occupational asthma and removed from exposure in the province of Québec between 1985 and 2002. J Occup Environ Med 2006, 48:1093-1098. 
32. Maghni K, Lemière C, Ghezzo H, Yuquan W, Malo JL: Airway inflammation after cessation of exposure to agents causing occupational asthma. Am J Respir Crit Care Med 2004, 169:367-372.

33. Ameille J, Pauli G, Calastreng-Crinquand A, Vervloët D, Iwatsubo Y, Popin E, Bayeux-Dunglas MC, Kopferschmitt-Kubler MC, and the corresponding members ofthe ONAP: Reported incidence of occupational asthma in France, 1996-99: the ONAP programme. Occup Environ Med 2003, 60:136-141.

34. Provencher S, Labrèche FP, De Guire L: Physician based surveillance system for occupational respiratory diseases: the experience of PROPULSE, Quebec, Canada. Occup Environ Med 1997, 54:272-276.

35. Beach J, Rowe BH, Blitz S, Crumley E, Hooton N, Russell K, Spooner C, Klassen T: Diagnosis and management of work-related asthma. In Evidence Report/Technology Assessment Number 129. Prepared for Agency for Healthcare Research and Quality, U.S. Department of Health and Human Services, 540 Gaither Road, Rockville, MD 20850: AHRQ Publication; 2005. www.ahrq.gov.

36. Karvala K, Uitti J, Luukkonen R, Nordman H: Quality of life of patients with asthma related to damp and moldy work environments. Scand J Work Environ Health 2013, 39:96-105.

37. Vandenplas $\mathrm{O}$, Dressel $\mathrm{H}$, Nowak $\mathrm{D}$, Jamart J: What is the optimal management option for occupational asthma? Eur Respir Rev 2012, 21:97-104.

38. Vandenplas $\mathrm{O}$, Dressel H, Wilken D, Jamart J, Heederik D, Maestrelli P, Sigsgaard T, Henneberger P, Baur X: Management of occupational asthma: cessation or reduction of exposure? A systematic review of available evidence. Eur Respir J 2011, 38:804-811.

39. Miedinger D, Lavoie KL, L'Archeveque J, Ghezzo H, Malo JL: Identification of clinically significant psychological distress and psychiatric morbidity by examining quality of life in subjects with occupational asthma. Health Qual Life Outcomes 2011, 9:76.

40. Miedinger D, Lavoie KL, L'Archevêque J, Ghezzo H, Zunzunuegui MV, Malo $J \mathrm{~L}$ : Quality-of-life, psychological, and cost outcomes 2 years after diagnosis of occupational asthma. J Occup Environ Med 2011, 53:231-238.

41. Lavoie KL, Joseph M, Bacon SL: Psychological distress and occupational asthma. Curr Opin Allergy Clin Immunol 2009, 9:103-109.

42. Rüegger M, Droste $D$, Hofmann M, Jost M: Socioeconomic consequences of isocyanate-induced occupational asthma: results of a 12-year follow-up study [abstract]. Swiss Med Wkly 2009, 139(suppl 171):6S

43. Piirilä PL, Keskinen HK, Luukonen R, Salo S-P, Tuppurainen M, Nordmann H: Work, Unemployment and Life Satisfaction among patients with diisocyanate induced asthma-a prospective study. J Occup Health 2005, 47:112-118.

44. Stanojevic S, Wade A, Stocks J: Reference values for lung function: past, present and future. Eur Respir J 2010, 36:12-19.

45. Swanney MP, Ruppel G, Enricht PL, Pedersen OF, Crapo RO, Miller MR, Jensen RL, Falaschetti E, Schouten JP, Hankinson JL, Stocks J, Quanjer PH: Using the lower limit of normal for the FEV1 /FVC ratio reduces the misclassification of airway obstruction. Thorax 2008, 63:1046-1051.

46. Pellegrino R, Viegi G, Brusasco V, Crapo RO, Burgos F, Casaburi R, Coates A, van der Grinten CPM, Gustafsson P, Hankinson J, Jensen R, Johnson DC, Maclntyre N, McKay R, Miller MR, Navajas D, Pedersen OF, Wanger J: Interpretative strategies for lung function tests. Eur Respir J 2005, 26:948-968.

47. Malo JL, Cartier A, Ghezzo H, Lafrance M, McCants M, Lehrer SB: Patterns of improvement in spirometry, bronchial hyperresponsiveness, and specific $\operatorname{lgE}$ antibody levels after cessation of exposure in occupational asthma caused by snow-crab processing. Am Rev Respir Dis 1988, 138:807-812.

48. Pride NB: Bronchial hyperreactivity in smokers. Eur Respir $J 1988,5: 485-487$.

49. Polosa R, Thomson NC: Smoking and asthma: dangerous liaisons. Eur Respir J 2013, 41:716-726.

50. Labrècque M, Malo JL, Alaoui KM, Rabhi K: Medical surveillance programme for diisocyanate exposure. Occup Environ Med 2011, 68:302-307.

51. Wilken D, Baur X, Barbinova L, Preisser A, Meyer E, Rooyackers J, Heederik D: What are the benefits of medical screening and surveillance? Eur Respir Rev 2012, 21:105-111.

\section{doi:10.1186/1745-6673-9-21}

Cite this article as: Rüegger et al:: Diisocyanate-induced asthma in

Switzerland: long-term course and patients' self-assessment after a 12-year follow-up. Journal of Occupational Medicine and Toxicology 2014 9:21.

\section{Submit your next manuscript to BioMed Central and take full advantage of:}

- Convenient online submission

- Thorough peer review

- No space constraints or color figure charges

- Immediate publication on acceptance

- Inclusion in PubMed, CAS, Scopus and Google Scholar

- Research which is freely available for redistribution

Submit your manuscript at www.biomedcentral.com/submit 